\title{
Redes e (inter)relações: A organização social da piscicultura em Maripá/PR
}

\author{
Networks and (inter)relations: The social organization of fish farming in Maripá/PR \\ Redes e (inter) relaciones: La organización social de la piscicultura en Maripá / PR
}

\section{Resumo}

O Paraná é o estado brasileiro que desponta como o maior produtor brasileiro de piscicultura. O oeste do Paraná, especialmente o município de Maripá, contribui significativamente para esse resultado. Neste sentido, objetivou-se compreender os aspectos dessa promoção da piscicultura no município de Maripá / PR. A teoria discutida, foi a do capital social, de Bordieu e Putnam, e sua relação com o desenvolvimento; a seguir, admitiu a ligação entre relações sociais e desenvolvimento econômico, de Bresser-Pereira. A metodologia: Inicialmente, buscou-se identificar as variáveis apresentadas em estudos anteriores; Em seguida, para a amostragem dos resultados, foi inserida a teoria de laços fortes e fracos, de Granovetter, com uso de Análise de Redes Sociais (ARS), de Marteleto; e diagramação gráfica com o software Ucinet ${ }^{\circledR}$. As considerações: Os agentes da cadeia da piscicultura (indústrias, produtores, mercados, universidades, órgãos reguladores, agências de assistência e crédito, entre outros) de Maripá estabeleceram estratégias de desenvolvimento baseadas nas dimensões do capital social (instituições de confiança, conduta, direitos e obrigações, entre outros). No entanto, ainda há necessidade de uma visão sustentável para dentro, sobre o comportamento institucional em relação ao meio ambiente.

Palavras-chave: Desenvolvimento; Capital social; Instituições; Comportamentos.

\begin{abstract}
Paraná is the Brazilian state that has emerged as the largest Brazilian producer of fish farming. The west of Paraná, especially the municipality of Maripá, contributes significantly to this result. In this sense, the objective was to understand the aspects of this promotion of fish farming in the city of Maripá/PR. The theory discussed was of social capital, of Bordieu and Putnam, and its relation with development; then, admitted the link between social relations and economic development, of Bresser-Pereira. The methodology: Initially, we sought to identify the variables presented in previous studies; Then, for the sampling of results, was entered the theory of strong and weak ties, of Granovetter, with use of Analysis of Social Networks (ARS), of Marteleto; and graphic diagramed using the Ucinet ${ }^{\circledR}$ software. The considerations: The fish farming chain agents (industries, producers, markets, universities, regulators, assistance and credit agencies, among others) from Maripá established strategies of development based on dimensions of social capital (trust, conduct, rights and obligations institucions, among others). However, yet there is need for a sustainable see inboard, about of institutional behavior to environment.
\end{abstract}

Keywords: Development; Social capital; Institutions; Behaviors.

\section{Resumen}

Paraná es el estado brasileño que se convertido en el mayor productor brasileño de piscicultura. El occidente de Paraná, especialmente el municipio de Maripá, contribuye significativamente a este resultado. En este sentido, el objetivo fue comprender los aspectos de esta promoción de la piscicultura en la ciudad de Maripá/PR. La teoría discutida fue la del capital social, de Bordieu y Putnam, y su relación con el desarrollo; luego, admitió el vínculo entre relaciones sociales y desarrollo económico, de Bresser-Pereira. La metodología: Inicialmente, buscamos identificar las variables presentadas en estudios previos; Luego, para el muestreo de resultados, se ingresó la teoría de vínculos fuertes y débiles, 
de Granovetter, con uso de Análisis de Redes Sociales (ARS), de Marteleto; y diagramado gráfico con el software Ucinet ${ }^{\circledR}$. Las consideraciones: Los agentes de la cadena piscícola (industrias, productores, mercados, universidades, reguladores, agencias asistenciales y crediticias, entre otros) de Maripá establecieron estrategias de desarrollo con base en dimensiones de capital social (instituciones de confianza, conducta, derechos y obligaciones, entre otras). otros). Sin embargo, existe la necesidad de una visión interna sostenible sobre el comportamiento institucional con el medio ambiente.

Palabras clave: Desarrollo; Capital social; Instituciones; Comportamientos.

\section{Introdução}

O desenvolvimento é um movimento cíclico que necessita de (inter)ações humanas para funcionar. As redes sociais estão presentes nas realidades vividas pelo indivíduo que habita na terra. Mesmo aquele que vive isolado, ainda sim tem dependência de outros “animais" da natureza (Heilbroner, 1996, p. 22, 40 e 126).

Neste contexto, com as relações sociais são possíveis materializar e imaterializar capitais dentro de uma sociedade (Heilbroner, 1996, cap. III e IV). Os capitais materializados são aqueles físicos ou tangíveis e palpáveis, como por exemplo as construções civis, produtos alimentícios, etc. E os capitais imateriais são aqueles emocionais ou simbólicos e não-palpáveis.

Os capitais sociais aparecem como capitais imateriais e são medidos pelas relações entre os indivíduos ou pela importância dada a um relacionamento (Bordieu, 2006). Nas palavras dos grandes cientistas sociais, Bourdieu e Putnam, o capital social está intimamente ligado as tratativas presentes nas redes de relacionamentos.

O capital social está presente nas cadeias produtivas globalistas. A ideia de globalistas, por Bresser-Pereira (2009), é que os países devem abrir suas portas para o comércio internacional. Para o desenvolvimento de uma nação (populações de um país) são necessárias estratégias sustentáveis para competir no mercado internacional. No entanto, o cientista disserta que se faz necessário pensar nas condicionalidades e restrições de seu país ou nação.

Por isso, são necessárias adoções de políticas de Estado (no Brasil, estipuladas por governos) concatenadas aos contextos sociais, econômicos, ambientais e culturais de cada identidade e característica regional demográfica.

Neste estudo, objetiva-se compreender os aspectos de promoção do setor produtivo piscícola, identificados em dois estudos aplicados, no município de Maripá/PR. No tocante ao município a ser estudado, tem-se que Maripá está no oeste do estado do Paraná e que essa região desponta como a líder no ranking da tilapicultura, importante subárea da piscicultura brasileira (PEIXEBR, 2021).

Então, questiona-se: Como as relações sociais entre os agentes do setor produtivo promoveram o desenvolvimento da piscicultura no município de Maripá/PR?

Para responder este questionamento, o estudo baseou-se nas teorias do capital social de Bordieu e Putnam e na teoria do desenvolvimento de Bresser-Pereira (2009). Como metodologia, foi utilizado a teoria dos laços, de Granovetter, a partir da Análise das Relações Sociais (ARS), proposto pela Marteleto (2001). Em seguida, tem-se os resultados e discussões, com o emprego de análises qualitativas, e por fim, apresenta-se as conclusões, daquilo que fora observado.

\section{Revisão Teórica: Capital Social}

\subsection{O capital social nas visões de Putnam e Bourdieu}

As discussões sobre capital social ficaram intensas a partir de 1990, disseminando-se a partir de 1993, com a obra de Robert Putnam "Comunidade e democracia: a experiência da Itália moderna". Entretanto, nos anos 80, havia discussão do capital social, a partir da visão de Pierre Bourdieu (1985).

Putnam (2006, p. 177), considerava que o capital social é formado por "confiança, normas e sistemas que contribuam para aumentar a eficiência da sociedade, facilitando ações coordenadas". O cientista enfatizou que a confiança, assim como as normas e redes de relações sociais são características específicas ao capital social - quanto maior for a utilização do capital 
social, maior será o crescimento e a presença de círculos virtuosos - demonstrando elevados níveis de cooperação, confiança em expansão e fortes níveis de reciprocidade e de atividade cívica.

Segundo Ortega e Matos (2013), a definição de Putnam sobre o capital social é que a relação social se sustenta por meio dos comportamentos de reciprocidade, as quais surgem a partir de interações em nível civil, em que pode ser formado por vilas, cidades, estados e até mesmo por países.

Em síntese, o capital social é baseado em confiança e reciprocidade, em que se necessita de organização social orientada para a determinação de normas e modelos comportamentais primordiais para a promoção da confiança social e interpessoal (Ortega \& Matos, 2013).

Putnam (2006), considera que quanto maior for o relacionamento entre pessoas, e ainda, quanto maior for a intensidade das relações sociais, considerando as características e valorização da cultura local, mais efetiva os comportamentos individuais e coletivos em prol do capital social.

Bourdieu (1985) por sua vez, se opõe a visão de Putnam e discorre sobre as fontes de capital social, a qual é formada por especificamente capital econômico (acumulo de riquezas) e capital humano (conhecimentos e habilidades), na qual o capital social consiste na essência das relações de uns com os outros, na qual é a genuína fonte de benefícios, na qual está "associado às suas ideias teóricas sobre classe" (Bourdieu, 2005, p. 23).

De tal modo, Bourdieu (2005, p. 24) entende o capital social formado por "um campo de lutas destinadas a conservar ou a transformar o campo de forças, um campo de ação socialmente construído onde se afrontam agentes dotados de recursos diferentes".

Segundo o autor, o fator econômico por si só não se pode ser considerado uma forma de capital, pois o capital social ocorre por meio de ralações em que as redes são importante condicionadores de capital social, pois, permitem além das relações, a compreensão das trocas de informações e conhecimento em que confere status social e poder, de tal modo, pode-se contribuir para a melhoria econômica como um todo (Bourdieu, 1985).

De acordo com Portes (2000), a definição de capital social descrita por Bourdieu é a que maior possui aplicação teórica na contemporaneidade. Para Bourdieu, são muitos os benefícios extraídos dessas redes, principalmente ao que concerne a solidariedade, no qual o autor afirma, que esta característica é a responsável pela base da formação das redes de relações.

As redes são constituídas além da solidariedade em investimentos em confiança, a fim de conquistar outros benefícios (Porter, 2000). Já Bourdieu (2010) destacava que o capital social proporciona acesso ao capital econômico, ou seja, o alcance a diversos recursos como empréstimos, informações de negócios, acesso a mercados, entre outros.

As redes seriam o aumento das probabilidades de realização, já que oferecem alternativas de relacionamentos. Para Bourdieu (2010), o capital social de cada agente depende significativamente das redes de relações em que os indivíduos passam a mobilizar e da capacidade econômica, cultural e simbólica que cada sujeito possui.

O capital social, antes de ser um conceito inteiramente inovador, busca recriar antigas noções de civismo comunitário. Neste contexto, destaca-se os estudos deste grande cientista social Pierre Bourdieu, pois abriram portas para o desenvolvimento de novas pesquisas e conceitos sobre o capital social.

Enfatiza-se que o capital social, na visão de Bourdieu (2010), são as relações constituintes por redes de relações duráveis, que possuem um acumulo de capital não financeirizado, mas utilizável na reprodução social. Pois Bourdieu (2004), realçava que o capital social no aspecto econômico, associa-se a ideia de poder, resultante da participação de um conjunto de agentes com características similares, visando a garantia de benefícios para um grupo específico e para benefício individual.

Neste sentido, o autor destaca que o capital social não é desenvolvido de forma autônoma e tampouco pela quantidade de poder que determinado agente exerce, mas sim, pelas informações e conhecimentos que essa rede de contatos possui (Bourdieu, 2006). 


\subsection{O capital social e sua relação com o desenvolvimento}

O processo de desenvolvimento como processo de inclusão social, originou-se nos séculos XVIII, mas ganhou maior destaque entre os séculos XIX e XX, a fim de buscar melhorar o acesso a bens materiais e culturais. Putnam (2006) em sua pesquisa na Itália percebeu que, apesar de determinadas regiões possuírem as mesmas políticas públicas, essas localidades podem apresentar resultados diferentes. Essas descobertas podem ser explicadas além de aspectos institucionais, com a finalidade de eliminar as desigualdades, mas também, à aspectos pertinentes a confiança, cooperação e reciprocidade entre os agentes de determinada região.

Putnam (2006), uma comunidade cívica se caracteriza por uma espessa rede de relações entre agentes locais, seja pela confiança e reciprocidade ou pelo cumprimento de normas e políticas sociais, de modo que quanto mais cívica é uma comunidade, melhor a eficácia governamental, bem como melhor as aplicações nestas comunidades.

O cientista social destacava quanto maior a participação dos agentes em associações de interesse comum, maior o estoque de capital social, visto que a troca de relações geram maior confiabilidade entre essa rede de relacionamento (Putnam, 2006).

Radomsky (2009) considerava que as redes de relacionamento geravam a reciprocidade, quanto ao desenvolvimento (o estudo falará mais sobre isso!). Ainda, na ideia do autor, a capacidade cooperativa entre os atores rurais é fundamental para gerar e agregar valor, reduzir custos e estimular a economia local.

Franco (2001) dissertou que as ações quando realizadas em comunidade, são capazes de interferir na vida dos agentes, especialmente na dos produtores rurais. Nota-se que mesmo a rede de relacionamento, sendo formada por pequenos grupos de pessoas, é possível democratizar e flexibilizar o processo de planejamento e prover a implementação de ações para o desenvolvimento de uma comunidade.

No entanto, o capital social com viés ao crescimento local para o se espera, que é o desenvolvimento, sofre impactos negativos, no que tange aos aspectos de poder e de política. A essa negatividade, implica-se nos construtos interativos para o desenvolvimento rural sustentável, pois para a efetividade do sustentável, deve ser observado com afinco nos campos sociológicos, ambientais, políticos e econômicos, intrínsecos na sociedade (Franco, 2001).

Cernea (1995) considerava que o desenvolvimento sustentável somente é possível a partir da participação da comunidade nas políticas e nos projetos de desenvolvimento, relacionados principalmente aos aspectos sociais, culturais, ambientais e econômicos. A partir dessa integração, nos campos de formulações de consultas, ideias e propostas, é possível gerar estoque de capital social, contribuindo de forma positiva para o desenvolvimento democrático da sociedade.

Já Barbosa e Neto (2016), consideraram que o processo de desenvolvimento rural somente é possível a partir da formação de redes entre os agentes transformadores do campo e os eficientes processos de organização, formando uma efetiva rede de interação do setor produtivo para prover o desenvolvimento rural sustentável.

Finaliza-se esta subseção, na obra de Amartya Sen (2000) em seu livro "Desenvolvimento como liberdade", o qual pondera que o desenvolvimento somente ocorre de forma efetiva, quando são considerados as liberdades socioeconômicas por meio de um conjunto de estratégias políticas e técnicas condizentes com os aspectos culturais da população envolvida, em que são protagonizadas manifestações solutivas.

Isto instiga interações entre as instituições que precisam visar o fortalecimento dos processos ao desenvolvimento econômico nacional.

\subsection{Desenvolvimento econômico e as relações sociais}

Diante dos cenários produtivos brasileiros e das relações que estão constituídas para o desenvolvimento, ainda é percebido que o desenvolvimento econômico aparece como o principal pilar direcionador de políticas públicas no Brasil. 
A concentração de maior poder de renda em uma pequena parcela da população, ainda é uma característica brasileira. Entretanto, a partir de possibilidades de formação de redes organizativas, com foco no desenvolvimento coletivo, há uma oportunidade cada vez mais efetiva para as cadeias produtivas brasileiras.

Em um resgate do desenvolvimento econômico brasileiro, tem-se o importante economista brasileiro Bresser-Pereira (2009), que busca suas compreensões nas interpretações de Celso Furtado - economista cepalino brasileiro, com grandes observações sob os países desenvolvidos e subdesenvolvidos - e de Raúl Prebisch - economista cepalino, com grandes observações nos contextos da América Latina. Evidencia-se que ambos economistas eram pesquisadores da CEPAL (Centro Estratégico e de Planejamento da América Latina) e que desenvolveram suas pesquisas relatando, especialmente, os acontecimentos das décadas de 1970-90.

Bresser-Pereira (2009), em seu livro "globalização e competição", promove um debate sobre o desenvolvimento econômico brasileiro, de forma focal ao cenário histórico que ele intitula "ortodoxia convencional" ou também chama de "velho" desenvolvimentismo e pensa em uma proposta estratégica de desenvolvimento, ao qual intitula "novo desenvolvimentismo". O cientista chama atenção em suas obras, que as realidades econômicas foram determinadas pelas "path dependence" (dependência da trajetória) e pelo "embebedness" (cultura enraizada). No entanto, a proposta do novo desenvolvimentismo é que haja um terceiro discurso que é a necessidade de reestruturação do sistema estratégico brasileiro.

Diante destes cenários nacionais, admite-se o estudo de Feijó da Silva et al. (2021) que apresenta as relações sociais como um meio para alcançar resultados positivos em determinado segmento. Neste contexto, os autores (Feijó da Silva et al., 2021) destacam o estudo de Regina Marteleto (2001) que trouxe um modelo de análise das relações sociais (ARS), sob a perspectiva da teoria do capital social de Putnam (1993) - dimensões de confiança, normas e sistemas - e na teoria dos laços de Granovetter (1974) - laços fortes e laços fracos.

A teoria lembrada dos laços fortes e fracos de Granovetter (1974), promove a agregação de valores entre os tecidos estruturais de determinada unidade de análise. Os fatores determinantes para a valoração dos objetos de análise são introduzidos mediante opinião (análise das perspectivas) dos próprios avaliados. Esta definição define as características do capital social, no que tange as dimensões de confiança entre os elos interessados, no conjunto de sistemas que a unidade de análise está inserida e nas normas (ou políticas) que regem a unidade.

A partir dessa teoria, Regina Marteleto (2001) propôs um modelo de análise capaz de ilustrar graficamente as relações sociais e seus valores existentes em uma unidade de análise. Ressalta-se que, ambos os autores partem dos pressupostos de desenvolvimento socioeconômico do qual a unidade de análise está inserida.

Posto isso, admite-se para esta pesquisa a teoria do desenvolvimento adotada foi a de Bresser-Pereira (2009), onde se tem propõe novas perspectivas estratégicas para o fortalecimento de uma nação.

\section{Materiais e Métodos}

Este estudo buscou analisar pesquisas aplicadas, de forma focal nos agentes sociais públicos e privados envolvidos na tilapicultura (subárea da piscicultura) de Maripá/PR (Figura 1). A abordagem é qualitativa-descritiva (Pereira et al., 2018). 
Figura 1: Mapa do estado do Paraná. Em destaque o município de Maripá.

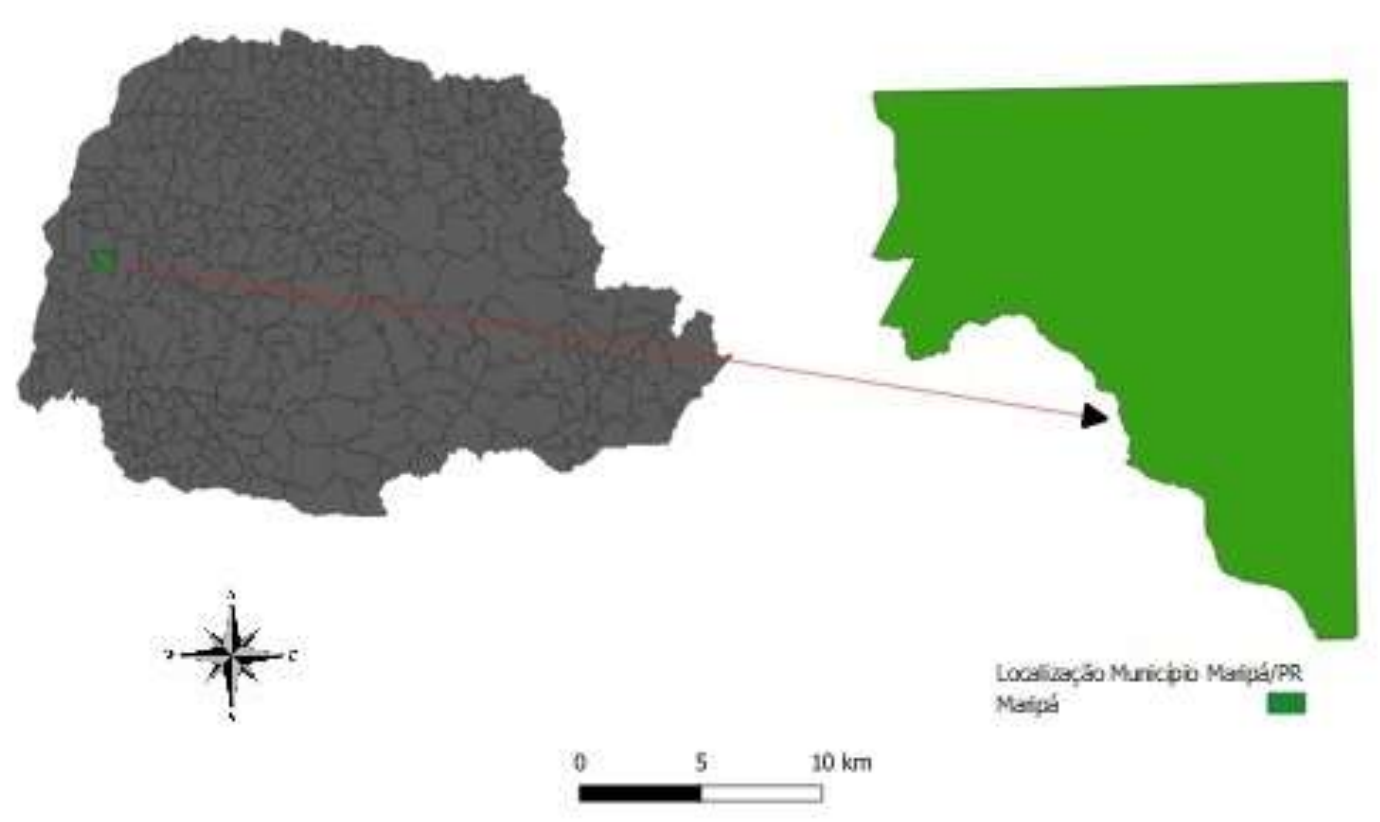

Fonte: Adaptado de IPARDES ITCG (2010).

Destaca-se sobre o município estudado que, antes de sua fundação, a economia era proveniente da agroextrativismo madeireiro, trabalho que propiciou riqueza ao desenvolvimento local. Por sua vez, atraiu a imigração populacional dos estados de Santa Catarina e de Rio Grande do Sul. O município foi criado pela Lei Estadual no 9.226 de 17 de abril de 1990, desmembrando-se do município de Palotina e emancipando-se em 18 de janeiro de 1993. Depois da emancipação, sua produção comercial era especialmente familiar, inicialmente com culturas de feijão, arroz, milho e mandioca, além da criação de animais em pequena escala. E atualmente, as principais atividades econômicas estão voltadas para a piscicultura, produção de orquídeas, avicultura, suinocultura, laticínios e produção de cereais (IPARDES, 2019).

Então, diante das pesquisas aplicadas de Feiden et al. (2018), Rech (2018) e Welter et al. (2021), foi utilizada a teoria dos laços fracos e fortes proposto por Granovetter (1973), que se propunha elucidar as dinâmicas interativas de capital social. A luz da teoria dos laços e do capital social, propõem-se o estudo das dimensões das propriedades comuns, permanentes e úteis (Feijó da Silva et al., 2021) dos produtores piscícolas e agentes sociais de Maripá/PR.

Ainda, com intuito de ilustrar as informações coletadas, oriundas da teoria dos laços fracos e fortes de Granovetter (1973), foi utilizada o instrumento de Marteleto (2001), intitulado Análise das Redes Sociais (ARS) com o emprego do software Ucinet ${ }^{\circledR}$ (Borgatti, Everett e Freeman, 2002). Essa metodologia, oriunda do campo das Ciências Sociais, foi também utilizada por Feijó da Silva et al. (2021), fazendo possível a visualização gráfica das estruturas sociais e dos sujeitos que a integram.

\section{Resultados e Discussões}

\subsection{Resultados}

O capital social compreende um conjunto de dimensões e definições que favorecem a compreensão do indivíduo e/ou instituição na sociedade. A dependência de fatores endógenos é uma característica marcante do capital social, que permite o estudo das relações sociais, em redes, das normas e condutas, e do principal motor para a promoção de uma atividade que é a confiança, aquela que é estabelecida entre as partes. 
Neste tópico, empreendeu-se as variáveis citadas nos estudos de Welter et al. (2021) - no texto intitulado “A piscicultura como atividade agropecuária propulsora do desenvolvimento local e regional: O caso do município de Maripá/PR” - e em Feiden et al. (2018) - no texto intitulado "A cadeia produtiva da tilápia no oeste do Paraná: uma análise sobre a formação de um arranjo produtivo local" - que desenvolveram atividades aplicadas no Oeste do Paraná. As variáveis foram resgatadas e transportadas ao software Ucinet ${ }^{\circledR}$, para aferir as relações entre elas (Figura 2).

Figura 2: Variáveis identificadas e suas relações.

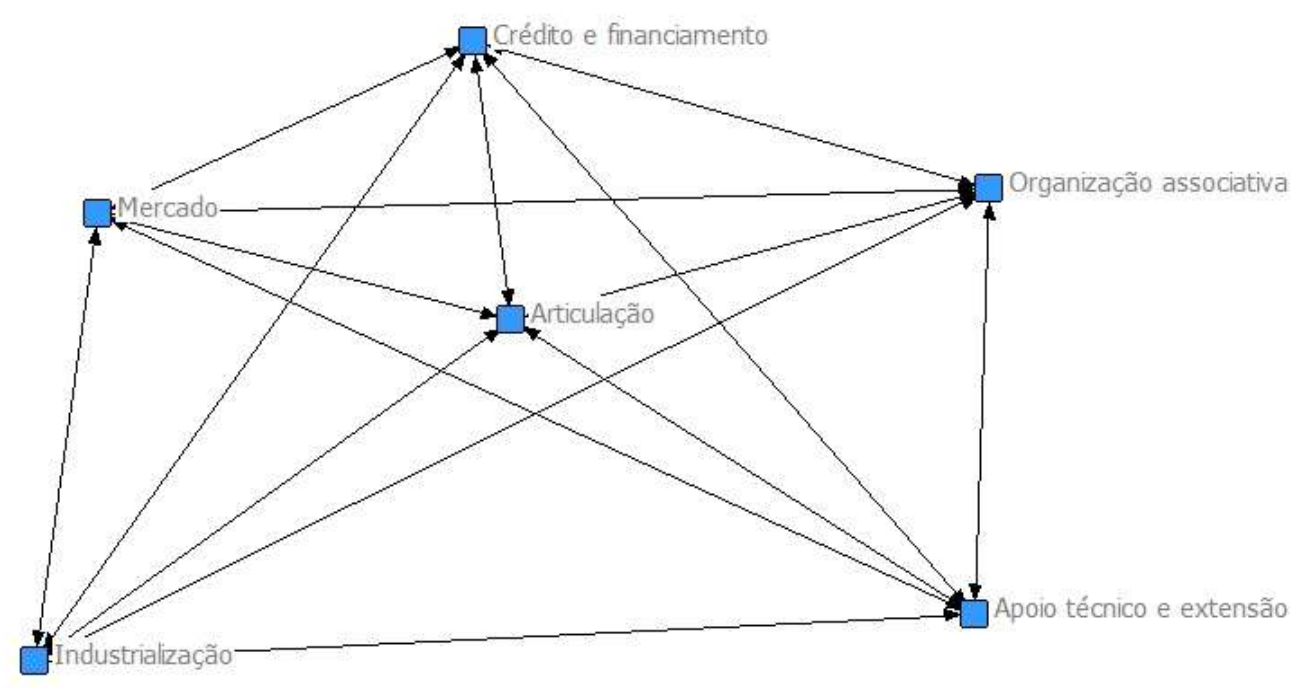

Fonte: Autores.

As relações das variáveis revelam que as partes necessitam estar interligadas para o desenvolvimento da piscicultura no Oeste do Paraná. O arranjo produtivo de Feiden et al. (2018) caracteriza as partes interessadas no desenvolvimento e ainda analisa cada parte no contexto das variáveis identificadas por esse estudo. O estudo de Welter et al. (2021), pois explicitamente os autores apresentam um caso de sucesso que é o caso de Maripá. Nas palavras dos autores, o município pode ser usado como molde para tecer novas estruturas de arranjos produtivos ou ecossistemas de produção.

Quando entrelaçados as variáveis identificadas nas pesquisas aplicadas com as dimensões do capital social de Bordieu e Putnam, é percebido interrelações e interdependências das variáveis às dimensões. O estudo faz cruzamentos entre as variáveis identificadas nos estudos de casos, as variáveis propostas por Putnam e as dimensões de Bordieu (Figura 3). 
Figura 3: Variáveis identificadas, dimensões de Bordieu e definições de Putnam e suas (inter)relações.

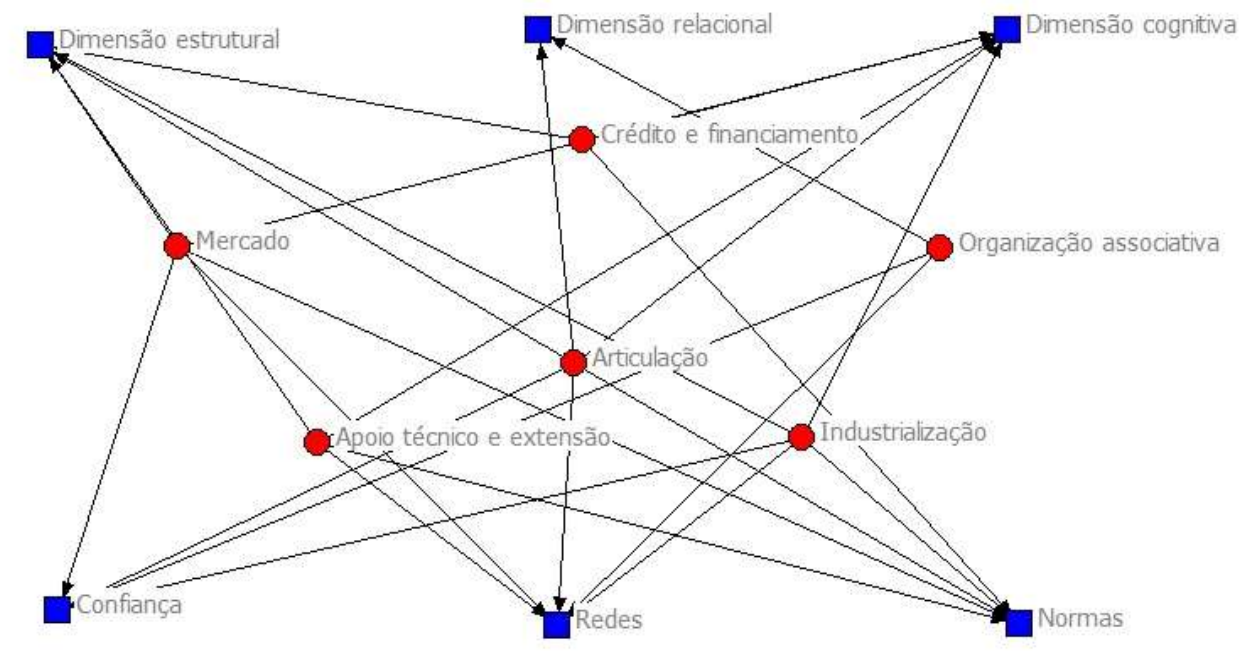

Fonte: Autores.

Readmitiu-se o software Ucinet ${ }^{\circledR}$, pois permitiu analisar as relações sociais, método desenvolvido por Marteleto (2001). A figura representa as interrelações e as interdependências que o arranjo produtivo da piscicultura paranaense deve ter, ou teve (caso de Maripá) para se desenvolver e despontar como o município líder no ranking de produtores de tilápias do Brasil (PEIXEBR, 2021). As relações de fraquezas e fortalezas (figura 4) da piscicultura do oeste paranaense, faz compreender que os apoios governamentais, no que tange aos órgãos assistenciais e fomentadores rurais, ainda são considerados fatores limitantes, que dificultam o desenvolvimento da piscicultura.

No entanto, os autores destacam que os produtores estão praticando as atividades conforme suas próprias estratégias de desenvolvimento. Os recursos intelectuais e financeiros dos produtores são escassos, mas estão sendo autogestionados na medida de suas estratégias de organização e articulação (Welter et al., 2021).

Figura 4: Análise das variáveis identificadas na teoria dos laços de Granovetter.



Fonte: Autores. 
No próximo tópico, serão discutidos os dados levantados e os estudos dos teóricos sobre as Análises das Relações Sociais.

\subsection{Discussões}

Por meio das análises gráficas é perceptível a interação dos agentes formadores de capital social, diante da visão de capital social de Putnam e Bordieu e de desenvolvimento de Bresser-Pereira, em que a interação dos agentes se desenvolve por meio das redes de relacionamento, da confiança e até mesmo pelas normas de funcionamento das atividades produtivas.

Por meio da teoria dos laços de Granovetter, foi possível identificar que os fatores condicionantes para o fortalecimento da piscicultura no município, destacada como laços fortes, se dá por meio da organização associativa dos piscicultores, as indústrias e os mercados. Logo, entende-se que os piscicultores conseguem desenvolver suas atividades pela demanda de produtos, em que os mesmos possuem abertura de onde ofertar através dos modus operandi das indústrias e dos mercados.

Porém, se faz importante reflexão quanto aos laços fracos, os quais são identificados pelo acesso ao crédito e ao apoia técnico e extensão. Debus (2016) constatou em seu estudo, que a piscicultura de Maripá/PR necessita de maior atenção, principalmente com relação ao emprego do apoio da assistência técnica e extensão. Dessa forma, é importante destacar que, o piscicultor é dependente de informações para melhor desenvolver suas atividades produtivas. Bem como, o acesso aos créditos precisa ser estruturado ou realinhado de acordo com as necessidades da cadeia produtiva da piscicultura, seja por meio de políticas públicas de acesso ou na facilidade burocrática de acesso.

Para instigar essa constatação, Putnam descreveu que os resultados das atividades produtivas podem ser diferentes para determinadas regiões, até mesmo quando apresentam as mesmas políticas públicas, sendo essas diversidades formadas por características culturais. Essa visão pode explicar a (inter)relação dos agentes transformadores na piscicultura de Maripá/PR.

Entender a cultura das pessoas se faz importante em um arranjo produtivo, para dedicar esforços em uma atividade que estaria de acordo com as características locais, sendo evidente no município de Maripá, a participação e a cultura das pessoas, os trabalhos realizados pelo poder público e o trabalho de empresas especializadas em suporte técnico e extensão, bem como, a atuação de associações e cooperativas organizadas pelos produtores rurais, que comumente atuam em conjunto (Feiden et al., 2018; Wendt e Schmidt, 2020; Welter et al., 2021).

Essa atuação conjunta entre os atores, é responsável pelo crescimento e fortalecimento dos círculos virtuosos descritos por Putnam. A cooperação entre os agentes torna as redes cada vez mais ligadas aos aspectos de confiança e reciprocidade (Welter et al., 2021). Franco (2001) analisou que as redes, mesmo sendo formadas por pequenos grupos de agentes, estes fortalecem o grau de relacionamento entre os agentes da cadeia produtiva, essa interação pode explicar o desenvolvimento positivo do município do setor piscícola em Maripá/PR.

Ao analisar as dimensões de Bourdieu, constata-se que na piscicultura de Maripá há interação das três dimensões apresentadas pelo autor, sendo elas: dimensão estrutural, dimensão relacional e cognitiva. No entanto, mesmo positivas, precisam estar continuamente gestadas estrategicamente com as variações do mercado.

Na dimensão estrutural de Maripá, a relação dos atores envolvidos no processo das redes de inter-relacionamento, no qual é perceptível o vínculo entre a indústria, os mercados, e o acesso ao crédito. Enfatiza-se que a presença das indústrias foram e somam importantes esforços para o desenvolvimento de mercados do setor. A disponibilidade de crédito para produção ainda é relativamente pequena, mas há iniciativas para rompimento dos paradigmas que assolam os iniciantes na atividade (Feiden $e t$ al., 2018). Esse inter-relacionamento contribui para a cooperação, sendo benéfica para a ação coletiva, em que os resultados apontam para o desenvolvimento positivo do capital social.

A dimensão relacional se dá por meio de aspectos comportamentais, ou seja, como os produtores de Maripá se interrelacionam umas com as outras. No estudo de Welter et al. (2021), foi constatado essa dimensão se dá por meio do respeito, 
amizade e confiança. Sabe-se que as relações são construídas, mas se os produtores estiverem obstinados na teoria do ganhaganha, essa relação é possível. Rech (2018), em seus escritos sobre a piscicultura, considera que o caráter associativista entre os atores é o que compõe as redes de relacionamento e foi fundamental para o desenvolvimento da atividade no município.

Já a dimensão cognitiva, imprescindível para o funcionamento de uma cadeia produtiva, deriva de processos mentais que resultam em ideias por meio da cultura e ideologia, como as normas, valores, atitudes e crenças, que contribuem para o interrelacionamento das redes. Na piscicultura da Maripá, essa interrelação ocorre entre os produtores rurais, o apoio de instituição de pesquisa e técnicos (profissionais liberais ou agentes do governo) e/ou extensionistas, os intermediadores de créditos (incluise aqui as agências de fomento privadas e públicas), e principalmente o emprego e o processamento das indústrias (inclui-se aqui instituições de processamento, entrepostos de beneficiamento, entre outros) e dos mercados (instituições de comercialização). Esses últimos atores mencionados, normalmente possuem um conhecimento maior sobre o funcionamento dos processos mercadológicos, das inovações, das normas, leis, regulamentos, e por meio destas informações conseguem desenvolver ideias, a partir da cultura e da ideologia dos piscicultores, para buscar desenvolver o setor no município.

Ainda, no estudo de Rech (2018), identificou-se que a piscicultura proporcionou melhorias nos aspectos de trabalho e renda, os piscicultores se adaptaram ao novo modelo de divisão do tempo, ou seja, a atividade não consiste em sazonalidade, o que garante renda durante o ano inteiro (métodos de trabalho que consiste na integração ou consórcio de sistemas produtivos).

Comparando o estudo a outros setores produtivos, é possível aferir os resultados parciais similares, ou seja, as cadeias produtivas se baseiam em condições de confiança. É como aponta o trabalho de Pereira, Schiavi e Guimarães (2019) na bovinocultura, onde discorrem que as redes de inter-relacionamento favoreceram os aspectos de confiança social e econômica do sistema de mercados, resultando na amenização de incertezas, diminuição de custos de monitoramento e nos custos de transação. Ainda apontaram que, o nível de confiança foi maior quando a participação de representantes institucionais foram intensas nas redes de relacionamento.

Interessante relatar também que no setor avícola do Ceará, na região nordeste do Brasil, Sousa (2017) considera que as redes de relacionamento aprisionam positivamente o acumulo de capital social, satisfazendo a concentração do setor e na ampliação dos mercados.

Já no setor leiteiro, percebe-se ainda mais profundamente a relação de aspectos dos fatores de capital social, principalmente ao que tange os laços fracos e fortes de Granovetter, em que é necessário uma maior concentração e interação de apoio técnico e extensionista aos produtores (Malagi, 2019). Nota-se que a confiança é o elemento principal e essencial para o fortalecimento da atividade leiteira.

Pereira, Schiavi e Guimarães (2019) ainda apontam que a confiança se estabelece por meio de três fontes, sendo: a) as redes, formados por amigos, familiares e pessoas com boa reputação social, relacionado aos laços fortes e fracos; b) das normas informais, comportamento e cultura dos grupos; e, c) por meio das trocas das organizações envolvidas.

Problema é que, infelizmente, como relata Rech (2018), o fator econômico tem ocupado um maior espaço e atenção entre os atores. Esse fato pode estar condicionado a pressão da produção em larga escala, resultando em impactos drásticos ao meio ambiente. Deste modo, é perceptível que, independentemente do setor produtivo, as redes de relacionamento sempre precisarão estar conectadas aos mercados, e são importantes fatores estratégicos para a consistência e desenvolvimento das atividades rurais sustentáveis.

\section{Considerações Finais}

As cadeias produtivas rurais brasileiras não são transformadas em casos de sucesso de forma imediata. São necessários planejamentos, educação ou reeducação daqueles que permeiam a atividade, envolvimento irrestrito das massas institucionais e 
o apoio incondicionais de apoios para o fortalecimento de mercados. As estruturações os envolvimentos diretos ou indiretas de representantes instituições nas cadeias produtivas formam o jargão estratégico para o desenvolvimento.

As análises dos ambientes piscícolas no município de Maripá/PR, permitiu entender o porquê do primeiro lugar no ranking brasileiro. O capital social da região Oeste do estado do Paraná, região que o município está inserido, permite que os produtores estabeleçam estratégias de confiança, normas, regulamentos, estruturas de conhecimento, para o despontamento de cadeias produtivas cada vez mais concatenadas com o desenvolvimento econômico do país.

No entanto, quando se volta o olhar para a sustentabilidade é importante frisar a importância do acompanhamento técnico e de extensão, a fim de identificar e auxiliar os possíveis processos de manejos adequados ao meio ambiente, reduzindo os impactos ecológicos, seja, no caso das pisciculturas, pelo desvio de água dos rios, para manter os açudes ou pela extensa quantidade de peixes por metro cúbico por açude, como forma de obtenção de maior lucratividade.

O conhecimento alienado com o bem-estar da sociedade, podem trazer novos horizontes para aquilo que se pretende com o desenvolvimento sustentável brasileiro. O progresso da humanidade, especialmente a brasileira, não está em degradar meios ambientes, mas promover tecnologias capazes de potencializar produções nos vários elos das cadeias produtivas.

Enfim, destaca-se que as interações interinstitucionais atribuem responsabilidades conjuntas, para as cooperações de indivíduos que compõem a sociedade. O caso da piscicultura de Maripá/PR solidifica e instiga a investidura de esforços para o olhar para dentro em cadeias produtivas rurais brasileiras. As organizações produtivas devem preocupar-se com os pressupostos endógenos característicos das regiões e garantir que os vários elos da cadeia estejam fielmente comprometidos com a teoria dos laços existentes.

O emprego do método utilizado neste estudo e uma possível investigação comparativa entre cadeias produtivas podem subsidiar a intenção de pesquisas futuras. Lembra-se que a intenção deste estudo não foi ditar uma "receita de bolo" de desenvolvimento de uma atividade produtiva, mas explicitar os fatores que promoveram a tilapicultura (subárea da piscicultura) do município Maripá/PR, colocando-a como um importante no ranking do estado do Paraná. A contraposição deste estudo é salutar para o debate dos fatores propulsores de cada região brasileira.

\section{Referências}

Barbosa, N. A., \& Neto, J. A. F. (2016). O capital social e sua contribuição para o desenvolvimento das regiões rurais. Revista Brasileira Multidisciplinar, 19(1), 124-138.

Borgatti, S. P., Everett, M. G., \& Freeman, L. C. (2002). Ucinet 6 for Windows: Software for Social Network Analysis. Harvard, MA: Analytic Technologies.

Bourdieu, P. (1985). The forms of capital. IN: Richardson, J. G. (org.), Handbook of Theory and Research for the Sociology of Education. Nova Iorque: Greenwood, 241-58.

Bourdieu, P. (2004). Coisas ditas. Brasiliense.

Bourdieu, P. (2005). O campo econômico. Política e Sociedade, (6), 15-57.

Bourdieu, P. (2006). As estruturas sociais da economia. Campo das Letras.

Bourdieu, P. (2010). Escritos de educação. Vozes.

Bresser-Pereira, L. C. (2009). Globalização e Competição. Elsevier.

Cernea, M. M. (1995). Primeiro la gente: Variables sociológicas em el desarollo rural. El Banco Mundial y Fondo de Cultura Económica.

Debus, D. (2016). Diagnóstico da piscicultura na agricultura familiar dos Municípios de Toledo/PR e Maripá/PR. 80 f. Dissertação (Mestrado em Desenvolvimento Rural Sustentável), Universidade Estadual do Oeste do Paraná. Marechal Cândido Rondon, PR, Brasil.

Franco, A. (2001). Capital social: leituras de Tocqueville, Jacobs, Putnam, Fukuyama, Maturana, Castells e Levy, Brasília: Instituto de Política Millennium.

Feiden, A., Ramos, M., Chidichima, A., Schmidt, C., Fiorese, M., \& Coldebella, A. (2018). A cadeia produtiva da tilápia no oeste do Paraná: uma análise sobre a formação de um arranjo produtivo local. Redes (St. Cruz do Sul Online), 23(2), 238-263. https://doi.org/10.17058/redes.v23i2.8992 
Research, Society and Development, v. 10, n. 13, e453101321037, 2021

(CC BY 4.0) | ISSN 2525-3409 | DOI: http://dx.doi.org/10.33448/rsd-v10i13.21037

Feijó da Silva, T., Ramos, T. C. da S., David, H. M. S. L., \& Vieira, A. C. T. (2021). Characteristics and specificities of the Social Network Analysis Methodology. Research, Society and Development, 10(3), e46510313622. https://doi.org/10.33448/rsd-v10i3.13622

Granovetter, M. (1974). Getting a job: a study of contacts and careers Cambridge, Harvard University Press.

Heilbroner, R. (1996). A história do pensamento econômico: os economistas. (5a ed.) Editora Nova Cultural.

IPARDES. (2010). Instituto Paranaense de Desenvolvimento Econômico e Social. Base de dados do Estado. http://www.ipardes.pr.gov.br/Pagina/BASE-DEDADOS-DO-ESTADO

Malagi, C. (2019). Rede leiteira do município de pato branco: análise a partir do capital social e das ações conjuntas desenvolvidas pelos participantes. Dissertação (Mestrado em Desenvolvimento Regional) Universidade Tecnológica Federal do Paraná. Pato Branco, PR, Brasil.

Marteleto, R. M. (2001). Análise de Redes Sociais - aplicação nos estudos de transferência da informação. Ciência da Informação, 30(1), 71-81

Ortega, A. C., \& Matos, V. A. (2013). Território, desenvolvimento endógeno e capital social de Putnam e Bourdieu. Política e Sociedade, 12(24), 36-60.

Pereira, J. A., Schiavi, S. M. de A., \& Guimarães, A. F. (2019). Capital social nas transações: estudo das relações de troca entre pecuaristas e suas cooperativas de abate no sistema diferenciado de carne bovina no estado do Paraná. XLIII Encontro da ANPAD. http://www.anpad.org.br/abrir_pdf.php?e=Mjc0MDU=

Pereira A. S. et al. (2018). Metodologia da pesquisa científica. UFSM.

Portes, A. (2000). Capital social: origens e aplicações na sociologia contemporânea. Sociologia, problemas e práticas, (33), $133-158$.

Putnam, R. (2006). Comunidade e Democracia: a experiência da Itália moderna. Fundação Getúlio Vargas.

Radomsky, G. W. (2009). Reciprocidade, redes sociais e desenvolvimento rural. IN: Schneider, S. A diversidade da agricultura familiar. (2a ed.), UFRGS, 107136.

Rech, C. M. (2018). Tratores, orquídeas e tilápias: uma análise sobre turismo e identidade de Maripá/PR. 105 f. Dissertação (Mestrado em História), Universidade Estadual do Oeste do Paraná. Marechal Cândido Rondon, PR, Brasil.

Sen, A. K. (2000). Desenvolvimento como liberdade. Companhia das Letras.

Sousa, B. N. F. de. (2017). O circuito espacial da produção avícola na região metropolitana de Fortaleza/Ce. Revista GeoNordeste, (2), $160-175$.

Welter, E. C., Riedo, I. G., Coldebella, A., \& Feiden, A. (2021). Fish farming as a local and regional development driving agricultural activity: The case of Maripá/PR. Research, Society and Development, 10(10), e95101018565. https://doi.org/10.33448/rsd-v10i10.18565

Wendt, E., \& Schmidt, C. M. (2020). Ações coletivas e ambiente empreendedor de Maripá/PR. Pretexto, 21(3), 49-68. 